\title{
O espiribol nas escolas públicas do município de Sombrio/SC: a memória coletiva em movimento
}

The spiribol in the public schools from Sombrio/SC city: the collective memory in movement

El espiribol en las escuelas públicas del municipio de Sombrio-SC: la memoria colectiva en movimiento

\author{
Bruna Toretti De Fáveri ${ }^{\mathrm{I}}$, Bruno Dandolini Colombo ${ }^{\mathrm{II}}$
}

\begin{abstract}
Resumo
O artigo teve por objetivo compreender como se deu a inserção do Espiribol nas escolas públicas de Sombrio/SC e como esta atividade da cultura corporal é abordada atualmente nas aulas de Educação Física deste município. A pesquisa foi de campo, em que foram realizadas entrevistas com quatro professores de Educação Física aposentados e dez professores que lecionam atualmente. Constatou-se que o Espiribol está inserido nas escolas do município desde a década de 70. Atualmente é abordado nas escolas como recreação, porém nas aulas de Educação Física a atividade não é tratada como conteúdo da Cultura Corporal.
\end{abstract}

Palavras-chave: Espiribol; Jogo; Escola; Cultura Corporal; Recreação

\begin{abstract}
The article aimed to understand how the insertion of the Espiribol in the public schools of Sombrio /SC was and how this Corporal Culture activity is approached in the Physical Education classes, currently, from this municipality. The research was the field one, in which interviews were conducted with four retired Physical Education teachers and ten teachers who teach nowadays. It was verified that the Espiribol has been inserted in the schools from Sombrio/SC since the decade of 70's. At the moment it is considered in the schools as it was recreation, but in the Physical Education Classes the activity is not treated as Corporal Culture content.
\end{abstract}

Keywords: Espiribol; Game; School; Corporal Culture; Recreation

${ }^{\text {I } U n i v e r s i d a d e ~ d o ~ E x t r e m o ~ S u l ~ C a t a r i n e n s e-~ U N E S C-C r i c i u ́ m a, ~ S C, ~ B r a s i l ~-~ E n d e r e c ̧ o: ~ E s t r a d a ~ G e r a l ~ S a n g a ~ N e g r a, ~ S o m b r i o, ~ S C, ~ B r a s i l-~ e-m a i l: ~ b r u h f a v e r i @ ~ h o t m a i l . c o m ~}$

${ }^{\text {II }}$ Universidade do Extremo Sul Catarinense- UNESC- Criciúma, SC, Brasil - e-mail: bruno@ unesc.net 


\section{Resumen}

Este artículo tiene como objetivo comprender como se ha dado la inserción del Espiribol en las escuelas públicas de Sombrio/SC y como esta actividad de la cultura corporal es abordada actualmente en las clases de educación Física de este municipio. La investigación ha sido de campo, realizada por medio de entrevistas con cuatro maestros de Educación Física jubilados y diez maestros que actúan. Se constató que el Espiribol se ha insertado en las escuelas del municipio desde la década 1970. En la actualidad es abordado en las escuelas como recreación, pero en las clases de Educación Física la actividad no es tratada como contenido de la Cultura Corporal.

Palavras clave: Espiribol; Juego; Escuela; Cultura Corporal; Recreación

\section{Introdução}

A pesquisa justifica-se pela relação proximal e histórica da acadêmica pesquisadora com o Espiribol. Residente do município há mais de 15 anos, ela recorda que o Espiribol se fez presente em sua vida escolar, na escola pública estadual no município de Sombrio/SC. Desde a $5^{\circ}$ série do Ensino Fundamental I, em 2006, a acadêmica praticava esta atividade da cultura corporal na hora do intervalo. Porém nas aulas de Educação Física o Espiribol nunca foi abordado de forma sistemática, como conteúdo da Cultura Corporal.

Durante as realizações dos estágios supervisionados obrigatórios do Curso de Licenciatura em Educação Física da Universidade do Extremo Sul Catarinense (UNESC) ${ }^{1}$, a acadêmica identificou, observando os intervalos e as aulas de Educação Física, o interesse dos alunos com o Espiribol.

Além do mais, tendo como pressuposto teórico a importância acerca da compreensão de uma atividade da cultura corporal considerando o seu desenvolvimento sócio- histórico dentro de uma comunidade e região, preservando a memória lúdica destas, (COLETIVO DE AUTORES, 2012), surgiu à necessidade de compreender como se deu a origem do Espiribol em Sombrio.

Com essa base teórica e a partir das experiências apresentadas acima com o Espiribol, como egressa de escola pública estadual do município e estudante do Curso de Educação Física da UNESC, constitui-se o seguinte problema de pesquisa: Como se deu a inserção do Espiribol nas escolas públicas de Sombrio/SC e como essa atividade da cultura corporal é abordada atualmente nas aulas de Educação Física das escolas públicas desse município?

Portanto, o objetivo geral da pesquisa é compreender como se deu a inserção do Espiribol nas escolas públicas de Sombrio/SC e como essa atividade da cultura corporal é abordada atualmente nas aulas de Educação Física das escolas públicas desse município.

E como objetivos específicos pretendem-se: Compreender a história do Espiribol, em geral no Brasil e em específico em Sombrio; Entender a inserção dessa atividade da cultura corporal no meio escolar do município de Sombrio a partir dos professores de Educação Física aposentados e atuais; E analisar de que forma o Espiribol é abordado atualmente pelos professores de Educação Física em seus planejamentos de aulas.

\footnotetext{
${ }^{1}$ A Universidade do Extremo Sul Catarinense é uma Universidade Comunitária localizada no município de Criciúma/SC, sul de Santa Catarina que fica aproximadamente $62 \mathrm{~km}$ da cidade de Sombrio/SC.
} 


\section{Metodologia}

A pesquisa de campo foi realizada por meio de entrevistas com professores de Educação Física aposentados e professores que lecionam atualmente em Sombrio. Depoimentos e informações foram recolhidos buscando compreender a história do Espiribol no município de Sombrio, da sua origem até a sua abordagem nas aulas de Educação Física nos dias atuais.

O objeto de estudo se caracteriza pela metodologia da História oral que segundo Delgado (2006) é um procedimento metodológico que busca por meio de documentos, registros e testemunhos, compreender a produção do conhecimento histórico, reconstituindo um processo coletivo em determinada comunidade.

A entrevista que foi utilizada para a coleta de dados é denominada de entrevista "semiestruturada", na qual o entrevistador realiza as perguntas, porém dependendo das respostas do entrevistado outras perguntas podem surgir. Assim informações importantes podem ser acrescentadas. De acordo com Gil et al. (2010, p. 76):

É "semiestruturada" quando o instrumento de coleta está pensado para obter informações de questões concretas, previamente definidas pelo pesquisador, e ao mesmo tempo, permite que se realizem explorações não previstas, oferecendo liberdade ao entrevistado para dissertar sobre o tema ou abordar aspectos que sejam relevantes sobre o que pensa.

O município de Sombrio-SC, localidade de análise da pesquisa, possui 09 escolas municipais, 05 escolas estaduais, 01 Instituição Federal e 02 escolas particulares. Devido à limitação de tempo com o cumprimento de datas para a entrega da pesquisa, a entrevista foi realizada apenas com professores de instituições públicas do município.

A recuperação da historicidade desta atividade no município de Sombrio é o ponto chave. E para compreender a origem, o contexto de como surgiu nas escolas o Espiribol, estabelecendo-se um fio histórico até a atualidade de sua abordagem no seio escolar, a entrevista será realizada com professores aposentados e atuais de Educação Física. A acadêmica visitou a Secretaria de Educação do município de Sombrio e perguntou sobre os professores aposentados do município. Com as informações recebidas, entrou em contato com 09 professores, por meio de redes sociais e contato pessoal, na qual 04 professores se disponibilizaram em contribuir com a pesquisa. Os demais aposentados, por motivos de problemas de saúde e viagem de negócios, não conseguiram tempo disponível durante o período da coleta de dados da pesquisa. Para a realização da entrevista com os professores que lecionam atualmente, foram selecionadas 03 escolas estaduais e 04 municipais que tenham a estrutura física minimamente adequada $^{2}$ para a prática do Espiribol e nas quais os alunos costumam praticá-lo, haja vista o contato anterior com todas as escolas públicas. Ao total, foram entrevistados 10 professores de Educação Física, que lecionam nos níveis escolares do Ensino Fundamental I e II, buscando identificar como essa atividade está sendo bordada nas aulas de Educação Física atualmente, bem como contribuir com aspectos históricos do Espiribol nas escolas públicas do município.

\footnotetext{
${ }^{2}$ Considera-se a estrutura minimamente adequada um espaço, pátio ou campo onde fixa-se o mastro, que por sua vez, suporte uma corda que amarre uma bola em sua ponta, em condições para a prática do Espiribol.
}

Revista Kinesis, Santa Maria, v. 38, p.01-12, 2020 


\section{0 espiribol no mundo, no Brasil ${ }^{3}$ e em Sombrio-SC ${ }^{4}$}

A origem do Espiribol é caracterizada por duas versões. De acordo com Escola (2014), acredita-se que este tenha surgido no século IX (801 até 900) originando-se da prática dos povos tártaros que tinham maior população na Rússia, Ucrânia e Cazaquistão, no século IX. Após guerrear, os povos tinham como costume atar a cabeça decepada dos inimigos e golpeá-la com pedaços de pau.

Outra versão é que o jogo surgiu na década de 1930, na cidade de Lanjarón município da província de Granada $^{5}$, onde um senhor chamado Baltasar Fábregas criou o jogo para diversão da família. O nome correto do jogo nessa província até os dias atuais é Spiribol, onde se jogam com raquetes e uma pequena bolinha amarrada em uma corda. O jogo tornou-se popular na província e difundiu-se pelo mundo (ESCOLA, 2014). Nos Estados Unidos, o Espiribol é conhecido como Tetherball sendo um dos jogos populares do país. No Brasil, o jogo sofreu transformações em sua vinda, as raquetes foram trocadas pelas mãos, a bola é maior e os mastros ganharam mais altura. (ESCOLA, 2014).

Kyle (2015) esclarece que o Espiribol é um jogo que consiste em uma bola especial de Espiribol, parecida com uma bola de voleibol, que, ligada a uma corda, está amarrada a um mastro de aproximadamente 3 metros do chão. Jogam dois ou quatro (em duplas) jogadores, no qual o objetivo é fazer com que a corda se envolva por completo em torno do mastro gerando um ponto para a dupla ou para o jogador que o fizer. O Espiribol pode ser praticado com as mãos ou raquetes.

Os saques iniciam o jogo. A dupla que conseguiu o ponto na rodada anterior faz o início da próxima rodada. O servidor lança a bola e bate-o na direção do receptor. Os jogadores não podem tocar na corda ou no mastro (também conhecido como pólo), não pode haver pausas da corda e bola. Os jogadores também não podem atravessar a linha que define o território do outro jogador. Os jogadores podem bater na bola apenas uma vez quando esta passa por seu território. Esses exemplos são considerados "faltas". Se qualquer uma dessas faltas está empenhada acidentalmente, a bola é envolvida em torno do polo na posição exata da falta e a pessoa que não cometeu a falta serve a bola em jogo (KYLE, 2015).

\footnotetext{
${ }^{3}$ Durante as pesquisas sobre o Espiribol no Brasil, não se conseguiu informações sobre em qual período este chegou ao referido país.

${ }^{4}$ O município de Sombrio/SC localiza-se no Extremo Sul do Estado de Santa Catarina, distante apenas 245 km da capital Florianópolis e aproximadamente $62 \mathrm{~km}$ de Criciúma. O município tem 26. 626 mil habitantes (IBGE, 2010).

${ }^{5}$ Em Peligros, comunidade localizada em uma província de Granada na Espanha, existe uma Organização sem fins lucrativos, a Fundação Spiribol criada em 2012, que é dedicada à integração de crianças de classes sociais carentes das localidades próximas (SPIRIBOL, 2012).
} 


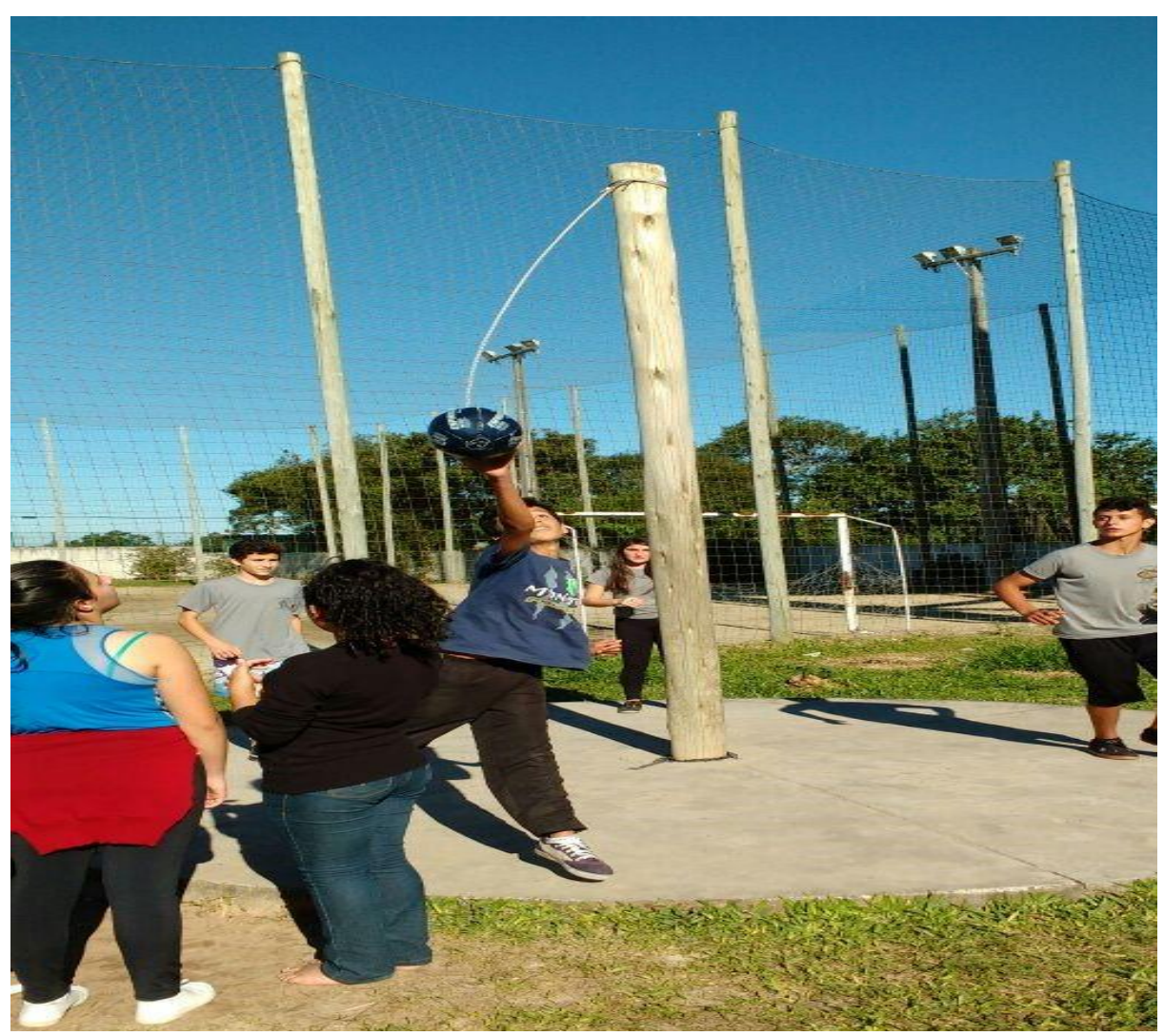

Imagem 1. Registro do Campo de Jogo/Estrutura Física e da prática do Espiribol pelos alunos, realizada pela acadêmica pesquisadora no dia 12 de Junho de 2017, em uma escola pública estadual do município de Sombrio.

Em nosso país algumas escolas promovem competições de Espiribol entre os alunos. A escola de São João Bosco em Minas Gerais promoveu um campeonato em que 16 duplas de jovens participaram durante três meses (de junho até agosto) com regras adaptadas (criadas) pela comunidade escolar (ESPORTES, 2016).

O município de Nova Araçá no Rio Grande do Sul realiza todos os anos a festa "Jogos Rurais de Integração". O objetivo da festa é a integração das famílias rurais por meio de práticas desportivas promovendo a interação social. Durante todo o dia, os moradores do município disputam 31 modalidades, entre elas: futebol sete, Espiribol, bocha, laço de vaca parada, etc. (RURAL 2016).

Segundo Witter (2016), a prática do Espiribol virou mania também nas escolas do município de Rio Grande no estado do Rio Grande do Sul. A escola Marista São Francisco elaborou um projeto chamado "Espiribol na escola", na qual regras do jogo foram apresentadas aos alunos. O objetivo do projeto é valorizar essa atividade recreativa praticada historicamente na escola.

Nas escolas públicas do município de Sombrio-SC, a atividade do Espiribol também é uma "febre". Algumas escolas têm dois ou três mastros do jogo que garantem a diversão dos alunos na hora do intervalo e nas aulas de Educação Física.

Destaca-se que o livro Sombrio: 85 anos natureza, história e cultura, escrito entre os anos de 1998 a 2002, pelo autor Vilson Farias, serviu de base para a presente pesquisa com informações importantes sobre a diversidade 
cultural do município, porém não foram encontrados registros e documentos abordando o Espiribol em Sombrio, o que nos levou, inclusive, a dedicar à pesquisa de campo, com abordagem da História Oral, ouvindo e registrando a memória dos professores de Educação Física pesquisados sobre a inserção dessa atividade da cultura corporal no município e nas escolas de Sombrio.

\section{Análise dos dados: a inserção do espiribol no meio escolar no município de Sombrio/SC}

A caracterização das análises de dados, a seguir, será sobre os professores aposentados de Educação Física de Sombrio. No primeiro momento foi relatado o perfil dos entrevistados e para manter a privacidade, utilizaram-se siglas fictícias para identificá-los. As siglas utilizadas foram: Letra A de aposentados e os números 01, 02, 03 e 04 referentes à quantidade de professores entrevistados.

Todos os 04 professores entrevistados formaram-se na Instituição de Ensino FUCRI ${ }^{6}$ (Fundação Educacional de Criciúma), em Criciúma/SC. Três deles concluíram a graduação na década de 80 e apenas o A1 na década de 60. Os entrevistados relataram que iniciaram o seu trabalho docente por meio de estágios e substituições entre os períodos dos anos 70 e 80 . Os entrevistados concluíram seu tempo de serviço no meio escolar entre os períodos do ano 2000 a 2016.

Questionados sobre a presença do Espiribol nas escolas que lecionaram, se havia a atividade e em qual momento era mais praticado, o entrevistado A1 citou a presença da atividade em uma escola estadual do município na década de 70. As entrevistadas A2 e A4 relataram a presença em escolas municipais e estaduais de Sombrio na década de 90 . Vale ressaltar que a entrevistada A2 observou pela primeira vez a atividade sendo praticada em duas escolas municipais na década de 90, na qual ela não atuou como docente, mas mencionou o professor ${ }^{7}$ de Educação Física responsável, nas escolas citadas por ela, em desenvolver a prática com os alunos.

O entrevistado A3 relatou que o Espiribol foi extinto no município de Sombrio a partir dos anos 95, devido à falta de estrutura e materiais. Somente nos anos de 2000 que a atividade volta a ser praticada nas escolas do município com auxílio da administração pública municipal.

Todos os professores relataram que o Espiribol sempre foi mais praticado durante o recreio/intervalo, bem como no decorrer das "saídas e entradas" das aulas. Somente as entrevistadas A2 e A4 abordaram dentro de suas aulas de Educação Física o Espiribol como um conteúdo, seja ele por meio de pesquisas, adaptações de regras, ou gincanas entre as turmas. A entrevistada A2 relata que o Espiribol chegou à escola municipal onde lecionava, entre o período de 2001 a 2003. Percebendo então o interesse dos alunos com o Espiribol, optou por trazer a atividade

\footnotetext{
${ }^{6}$ A Fucri é mantenedora da primeira escola de nível superior do Sul de Santa Catarina. A instituição foi criada em 22 de junho de 1968 . Em 17 de junho de 1997, o Conselho Estadual de Educação aprovou a transformação em Universidade do Extremo Sul Catarinense (UNESC), tendo a Fucri como sua mantenedora (UNESC, 2017).

${ }^{7}$ Não foi possível entrevistar o professor citado pela entrevistada, recorrente ao seu falecimento. Acredita-se que suas memórias e relatos seriam enriquecedores para a construção e desenvolvimento da pesquisa.
} 
como modalidade no Interséries ${ }^{8}$ da escola, para promover a socialização entre os alunos com algo que era bastante praticado por eles. Ela também relatou que solicitava aos alunos das turmas do Ensino Fundamental II, pesquisas sobre as regras do Espiribol, nos laboratórios de informática da escola. A partir disso, novas regras foram construídas pelos alunos, adaptadas de acordo com seus interesses, como, por exemplo, permitir rebater a bola com a mão fechada.

A entrevistada A4 afirmou que solicitou aos alunos que trouxessem as regras criadas por eles mesmos em uma gincana promovida pela escola. Nenhuma outra abordagem de conteúdo da atividade nas aulas foi citada pela entrevistada.

Os entrevistados tiveram experiências como professores e secretários regionais em outros municípios da região da $\mathrm{AMESC}^{9}$. Com isso, foram questionados sobre a incidência do Espiribol nesses municípios. O entrevistado A1 citou a incidência muito forte do Espiribol na cidade de Araranguá/SC, quando levava seus alunos para a competição do JERVA ${ }^{10}$ (Jogos Escolares da Região do Vale de Araranguá). Nas escolas onde ficavam alojados durante as competições, o entrevistado observou a prática frequente dos alunos do município, isso em meados da década de 80 e 90.

O entrevistado A3 também observou a "febre" da atividade do Espiribol no município de Araranguá, em quase todas as escolas, quando ocupava o cargo de Secretário Regional da AMESC, no final da década de 90 para início dos anos 2000. A entrevistada A4 observou a incidência em uma escola particular de Araranguá/SC na década de 90, quando se deslocava até a instituição de ensino para realização de cursos de capacitação pedagógicos ou reuniões escolares. Apenas a entrevistada A2 mencionou que observou pela primeira vez o Espiribol no município de Balneário Gaivota/SC, no entanto, destacou que não lecionou nesse município. Outros municípios que tinham a incidência da atividade citados pelos entrevistados A1 e A4 foram Santa Rosa do Sul-/SC e São João do Sul/SC, entre o período de 70 e 90.

Quando questionados sobre a existência do Espiribol nas escolas que lecionaram, se já havia, ou alguém o introduziu, o entrevistado A1 afirmou estar presente na escola o Espiribol na década de 70. A entrevistada A4 afirmou que ela, juntamente com um professor de Artes da escola, conseguiu um mastro pequeno para os alunos brincarem no recreio. Isso no início da década de 90.

As respostas que se identificaram foram dos entrevistados A2 e A3, sendo que o A3 quando assumiu o cargo de Secretário de Educação do município de Sombrio, após ter identificado o interesse pelo Espiribol na cidade de Araranguá, resolveu investir em materiais (mastros, cordas e bolas) e todas as escolas do município começaram a praticar o Espiribol novamente por volta do ano de 2003. A entrevistada A2 faz menções durante a entrevista sobre

\footnotetext{
${ }^{8}$ Os Interséries são jogos escolares realizados entre as turmas de uma escola. Várias modalidades como Futsal, Voleibol, Basquete, Tênis de Mesa, entre outros esportes e jogos são disputados entre os alunos.

${ }^{9}$ Associação dos Municípios do Extremo Sul Catarinense. Associação que atende 15 municípios ao total, abrangendo 170.000 mil habitantes. Disponível em: http://www.cisamesc.com.br/. Acesso em: 10 de Junho de 2017.

${ }^{10}$ JERVA. Tem como finalidade desenvolver o intercâmbio sócio -esportivo entre os municípios da Região da AMESC. Os municípios que participam são de Maracajá até Passo de Torres. As modalidades disputadas são: Atletismo, Basquetebol, Futsal, Handebol, Voleibol, etc. Disponível em: http://www.ritmodoesporte.com.br/images/Competicoes/Regulamentos/744.pdf. Acesso em: 10 de Junho de 2017.
} 
o incentivo da Secretaria de Educação por volta do ano 2003 em reafirmar a prática do Espiribol nas escolas municipais.

Em relação à abordagem do Espiribol como conteúdo na aula de Educação Física pelos professores aposentados, os entrevistados A1 e A3 afirmaram que não trabalharam como conteúdo, por se tratar de uma estrutura física inadequada, em que havia poucos mastros na escola, não sendo compatível com o número de alunos por turma, esclarecendo que suas aulas eram elaboradas para abranger o maior número de alunos ao mesmo tempo.

Como mencionado anteriormente, somente às entrevistadas A2 e A4 abordaram o Espiribol em seus planejamentos de aula. A2 abordou regras e a atividade dentro do Interséries, e a entrevistada A4 em forma de gincana.

Reflete-se, por meio das falas dos professores aposentados, uma incidência do Espiribol na cidade de Araranguá/SC e região entre as décadas de 70 e 90. Em Sombrio a prática da atividade vem com mais intensidade, abrangendo maior número de escolas, a partir dos anos 2000, quando há um incentivo por parte da Secretaria de Educação Municipal, na compra e instalação dos materiais necessários para a prática da atividade.

Reflete-se também que a ação objetiva de praticar o Espiribol como recreação nas escolas, pelos alunos, pode ser identificada nas falas dos entrevistados. Porém a apropriação do Espiribol como conteúdo, em seus aspectos históricos, lúdicos, técnico-táticos, bem como problematizações e ampliações científicas acerca dessa atividade da Cultura Corporal, foram oportunizadas aos alunos, de forma restrita.

Eis a importância do trato do conhecimento do Espiribol como conteúdo da Cultura Corporal, mesmo porque, de acordo com o Coletivo de Autores (2012, p. 63): "o aprofundamento sobre a realidade através da problematização de conteúdos desperta no aluno curiosidade e motivação, o que pode incentivar uma atitude cientifica".

\section{O espiribol e sua abordagem atual nas aulas de educação física de Sombrio/SC}

A caracterização a seguir será sobre os professores de Educação Física que lecionam atualmente em Sombrio/SC. No primeiro momento apresentar-se-á os perfis dos entrevistados e para manter a privacidade destes, utilizando-se a sigla fictícia L (de lecionam) para identificá-los e os números de 01 até 10 referentes à quantidade de professores entrevistados.

Todos os 10 entrevistados concluíram suas graduações entre os períodos dos anos 1990 a 2014. Os entrevistados formaram-se nas na UNESC, Universidade Federal de Santa Catarina (UFSC), Universidade Luterana do Brasil (ULBRA) e a antiga FUCRI. As situações funcionais dos professores dividiram-se, pois apenas duas das entrevistadas são $\mathrm{ACT}^{11}$ na Rede Municipal e Estadual de ensino e os demais como Efetivos na rede estadual e municipal.

A acadêmica pesquisadora questionou os entrevistados se estes observaram o interesse dos alunos em praticar a atividade do Espiribol nas escolas. Sendo que nove (09) dos professores afirmaram ter observado o interesse dos

\footnotetext{
${ }^{11}$ Admitido em caráter temporário na Rede de educação estadual e municipal de Santa Catarina.
} 
alunos com o Espiribol principalmente nos recreios/intervalos. Apenas a entrevistada L6 afirmou que seus alunos (Fundamental II) não possuem interesse pela atividade e o entrevistado L8 esclareceu que devido à construção do novo prédio escolar, há dois anos, a estrutura física do Espiribol ainda não foi instalada no pátio da escola ${ }^{12}$.

Questionados sobre a presença do Espiribol em outros municípios da região da AMESC, os entrevistados afirmaram que observaram a incidência da atividade em municípios como Araranguá/SC, Maracajá/SC, Santa Rosa do Sul/SC e Balneário Gaivota/SC. A entrevistada L10 afirmou que a técnica das rebatidas e a prática em si eram mais desenvolvidas pelos alunos no município de Sombrio.

Quando questionados sobre abordar o Espiribol como conteúdo nas aulas de Educação Física, 04 dos 10 entrevistados afirmaram trabalhar o Espiribol em suas aulas. A entrevistada L2 esclareceu que adaptou outras brincadeiras dentro do jogo do Espiribol, como a "bola voadora", em que os alunos quando eliminados na queimada deveriam permanecer dentro dos limites do campo de jogo do Espiribol. Os entrevistados L8 e L9 contextualizam que trabalharam o rodízio, as regras básicas do Espiribol, percepção de espaço e a maneira correta de rebater a bola. O entrevistado L4 afirmou que o Espiribol faz parte de suas aulas, mas não deixou claro de que forma a atividade é desenvolvida.

Diante dessas respostas, percebe-se que os entrevistados abordam apenas as regras básicas e, de certa forma, a técnica do Espiribol nas aulas de Educação Física, desconsiderando o ensino dos aspectos históricos, políticos, mercadológicos, técnico-táticos e lúdicos dessa atividade da Cultura Corporal. De acordo com o Coletivo de Autores (2012), o conteúdo deve ser abordado dentro de sua totalidade, pois permite ao aluno constatar, interpretar, compreender e explicar sua realidade social. $\mathrm{O}$ aluno vai se apropriando de um pensamento mais elaborado por meio do conhecimento científico transmitido em seu meio escolar.

Os demais entrevistados 06 dos 10 professores de Educação Física, não abordam o Espiribol como conteúdo em suas aulas, devido alguns motivos. O mais citado é a falta de materiais em boa qualidade ${ }^{13}$, além da pouca quantidade de mastros referentes ao número de alunos por turma, por exemplo, dois ou três mastros para 30 alunos. A entrevistada L5 esclareceu não abordar como conteúdo, por se tratar de uma atividade que os alunos conhecem, dando ênfase em desenvolver atividades diferentes com os alunos. Questiona-se então, a partir desse relato da entrevistada: Será que os alunos realmente conhecem o Espiribol?

Por sua vez, a entrevistada L1 afirmou que a estrutura não é adequada à idade dos alunos, sendo que os menores não conseguem realizar as rebatidas e nem enrolar toda a corda no mastro, que é o objetivo do jogo, não a permitindo, de certa maneira, abordar o Espiribol como conteúdo. Diante disso, no entanto, é importante ter-se em vista que a adaptação da corda ou até mesmo da bola, possibilita a adequação as possibilidades sociocognoscitivas, fazendo com que o professor tenha "competência para adequar o conteúdo a capacidade cognitiva e a prática social

\footnotetext{
${ }^{12}$ Em uma conversa informal com funcionários da direção da escola, estes afirmaram que na antiga escola havia mastros e uma estrutura adequada para praticar a atividade do Espiribol. Atualmente a direção está providenciando os materiais necessários para que os alunos voltem em breve a praticá-lo na nova escola.

${ }^{13}$ Em conversas informais com funcionários da direção das escolas, algo que ficou muito evidente, foi a falta de uma estrutura adequada e materiais próprios para a prática. Os funcionários informaram que os pedidos dos materiais são feitos a Secretaria do Estado. Porém há uma demora na vinda destes materiais, ou então o pedido não é atendido devido às faltas de verbas financeiras.
} 
do aluno, ao seu próprio conhecimento e às suas possibilidades enquanto sujeito histórico" (COLETIVO DE AUTORES 2012, p. 33).

Outra fala importante de ser ressaltada é da entrevistada L6 que esclareceu não trabalhar com o Espiribol, pois essa atividade não consta na proposta curricular do município ${ }^{14}$. Destaca-se assim a importância de o corpo docente dos professores discutirem a possibilidade de inserir na seleção dos conteúdos da proposta a atividade do Espiribol, sendo que é algo tão presente na realidade escolar dos alunos, mesmo porque a Relevância Social do Conteúdo $^{15}$ é um dos princípios curriculares no trato do conhecimento apontado pelo Coletivo de Autores (2002) na seleção do conteúdo a ser abordado na escola.

\section{Considerações Finais}

Em relação ao entendimento acerca da inserção desta atividade da cultura corporal no meio escolar do município de Sombrio/SC conseguiu-se chegar a alguns esclarecimentos. O Espiribol estava presente desde a década de 70 no município de Sombrio, porém devido a problemas de estruturas e materiais, a prática da atividade do Espiribol na cidade entrou em extinção no período correspondente aos anos 95 a 2000. Logo nos anos 2003 com o auxílio da administração política municipal ele é reafirmado novamente como atividade nas escolas do município de Sombrio, por conta de um investimento na estrutura física e materiais necessários para a prática do Espiribol.

Pelos fatos levantados pelos entrevistados, principalmente pelos aposentados, acredita-se que o Espiribol estava inserido no município de Araranguá/SC - bastante citado pelos pesquisados - e demais municípios da AMESC, na década de 70, pois os professores aposentados e atuais afirmaram que o Espiribol já era uma prática presente na vida dos sujeitos dessa região. Portanto, destaca-se a importância de realizar-se uma pesquisa em Araranguá e em toda a região da AMESC sobre a incidência do Espiribol nesses municípios para melhor compreensão sobre a influência dessa atividade da cultura corporal na vida dos alunos.

Conseguiu-se analisar que a sua abordagem enquanto conteúdo nas aulas de Educação Física é um reflexo de uma prática enraizada no passado. Por meio das entrevistas com os professores aposentados e atuais, em sua maioria, estes afirmaram não trabalhar, de maneira sistemática e totalizante, o Espiribol como conteúdo de suas aulas de Educação Física escolar. De acordo com o Coletivo de Autores (2012), é importante compreender a totalidade do Espiribol por ser tratar de uma atividade da cultura corporal em que possui múltiplos aspectos - históricos, técnicotáticos, políticos e lúdicos.

Considera-se necessário que os professores de Educação Física que atuam nas Redes Públicas de ensino Estadual e Municipal- de Sombrio discutam a possibilidade de inserção dessa atividade como conteúdo nas aulas de

\footnotetext{
${ }^{14}$ No início do corrente ano, os professores efetivos da Rede de Ensino Municipal de Sombrio juntamente com o corpo de profissionais da Secretaria de Educação do município, se reúnem com o objetivo de elencar os conteúdos para serem trabalhados durante o ano letivo nas escolas. Conteúdos e formas de trabalhá-los são abordados, a fim de todos seguirem uma mesma proposta e uma mesma linha de ensino.

15 A Relevância social deve estar vinculada a explicação da realidade social concreta e oferecer condições para a compreensão dos determinantes sócio- históricos do aluno, particularmente de seu meio social (COLETIVO DE AUTORES, 2012).
} 
Educação Física durante o planejamento participativo, que acontece no início do ano letivo, realizado em conjunto com a Secretaria de Educação. Mesmo porque, os conteúdos selecionados, organizados e sistematizados devem promover uma concepção científica de mundo, a formação de interesses e a manifestação de possibilidades e aptidões para conhecer a natureza e a sociedade (COLETIVO DE AUTORES, 2012. p. 85). Assim, além do afirmado, destacase a importância de se pensar a introdução do Espiribol nos Jogos Municipais entre as escolas, já que é bastante praticado na cidade, possibilitando o estudo mais completo dessa atividade da Cultura Corporal, pelos professores e a transmissão do conhecimento científico para os alunos.

Em relação à estrutura física do Espiribol, como mastros, cordas e bolas em boas condições para serem utilizadas, sabe-se que há todo um sistema por trás, tratando-se de questões financeiras, materiais solicitados que não chegam à escola, entre outros. Porém, releva-se aqui que cabe a Rede de Ensino responsável, a direção da escola e o corpo docente, não deixarem de medir esforços para organizar o tempo e o espaço pedagógico necessários para a aprendizagem dos alunos. Possibilitando condições objetivas para transmissão do conhecimento, a escola deve organizar devidamente os espaços físicos e pedagógicos (quadras, bibliotecas, campos), com manutenção periódica, a fim de possibilitar aos alunos a aprendizagem.

É fundamental que os alunos do município possam ter a possibilidade de investigar a origem do Espiribol, seu contexto no meio em que está inserido, sua história e sua prática. Assim, ele permanece vivo na memória coletiva do município.

\section{Referências}

COLETIVO DE AUTORES. Metodologia do ensino de Educação Física. São Paulo: Cortez, 2012.

DELGADO, Lucilia de Almeida Neves. História Oral: memória, tempo, identidades. Belo Horizonte: Autêntica, 2006. $136 \mathrm{p}$.

ESCOLA. Espiribol na Escola. 2014. Disponível em: <http://educfisicaemfoco.blogspot.com.br/2014/11/Espiribolna-escola.html>. Acesso em: 20 de Set. 2016.

ESPORTES, Travinha. História e Regras do Espirobol. Disponível em: <http://www.travinha.com.br/esportesestranhos/188-espirobol/222-espirobol-o-jogo>. Acesso em: 20 set. 2016.

FARIAS, Vilson Francisco. Sombrio: 85 anos natureza, história e cultura. Sombrio, 2000.

GIL, Juana Maria Sancho et al. A Pesquisa Qualitativa na Educação Física: Alternativas Metodológicas. 3. Ed. Porto Alegre: Sulina, 2010.

KYLE, Clayton. Official Tetherbal IRules. 2015. Disponível em: <http://www.livestrong.com/article/206694official-tetherball-rules/>. Acesso em: 20 set. 2016.

RURAL, Página. RS: em Nova Araçá, jogos rurais de integração vão mobilizar oito municípios da Serra. 2016. Disponível em: <.>. Acesso em: 20 set. 2016.

SOMBRIO, Município de. Portal do Cidadão. Disponível em: <http://www.sombrio.sc.gov.br/cms/pagina/ver/codmapaItem/68835>. Acesso em: 22 nov. 2016. 
SPIRIBOL, Fundación. Fundación Spiribol: Juega, aprende, ayuda. 2012. Disponível em: <http://www.fundacionspiribol.com/>. Acesso em: 30 mar. 2017

UNESC, Portal da. Início, reitoria, histórico. Disponível em: 〈http://www.unesc.net/portal/capa/index/91/5085〉. Acesso em: 22 de maio 2017.

WITTER, Roberto. Espirobol vira mania em escola de Rio Grande. 2016. 2016H[q]bol-vira-mania-em-escola-derio-grande/>.>. Acesso em: 20 set. 2016.

\section{Como citar este artigo}

DE FÁVERI, Bruna Toretti; COLOMBO, Bruno Dandolini. O espiribol nas escolas públicas do município de sombrio/SC: a memória coletiva em movimento. Revista Kinesis, Santa Maria, v. 38, p.01-12, 2020. 